\title{
Editorial: Special Issue on "Human Bond Communications (HBC)”
}

\author{
Ramjee Prasad $^{1} \cdot$ Marina Ruggieri $^{2}$
}

Published online: 17 March 2016

(C) Springer Science+Business Media New York 2016

The 17th Edition of the closed-door Strategic Workshop was held in Villa Mondragone, Italy from the 18th to the 20th of May, 2015. The focus during the active 2-day discussions of the participating major stakeholders was on HBC, addressing concept, systems, network security, and future strategy.

The theme for the Strategic Workshop 2015 (SW' 15) was Human Bond Communications (HBC): The Human Bond Communications (HBC) is a holistic approach to describe and transmit the features of a subject in the way human perceives it. This communication will involve all the five senses for modelling the physical subject into information domain, actuating and transmitting through communication platform. This will let the physical subject to be understood by two mutually agreeing users of Human Bond Communications in the way subject observed by individual users separately.

Modern dexterous communication technology is progressively enabling humans to communicate their information through them with speech (aural) and media (optical) as underpinning essence. Humans realize this kind of aural and optical information by their optical and auditory senses. However, due to certain constraints, the ability to incorporate the other three sensory features namely, olfactory, gustatory, and tactile are still far from reality. Human Bond Communications is a novel concept that incorporates olfactory, gustatory, and tactile that will allow more expressive and holistic sensory information exchange through communication techniques for more human sentiment centric communication. This concept

Selected Topics from the Strategic Workshop, May 18-20, 2015, Villa Mondragone, in the vicinity of Rome, Italy.

Ramjee Prasad

prasad@es.aau.dk

1 Department of Electronic Systems, Center for TeleInFrastruktur, Frederik Bajers Vej 7, C1-107, 9220 Aalborg, Denmark

2 Center for Teleinfrastructures (CTIF), University of Roma "Tor Vergata", Rome, Italy 
endorses the need of inclusion of other three senses and proposes an innovative approach of holistic communication for future communication network.

This Special Issue features eight selected papers on the above topic that concentrate on a wide range of problems in the way $\mathrm{HBC}$ will be realized effectively based on smart communication. The HBC relies amply on emotions and person specific information, therefore, effective reliability, trust, and security will have to be considered.

The first paper, "Human Bond Communications: Generic Classification and Technology Enablers", by Liljana Gavrilovska and Valentin Rakovic provides a survey of the existing and most recent works that focus on the vision as well as the core technical enablers of the HBC paradigm. It discusses and identifies the key challenges for the future research directions and the ongoing $\mathrm{HBC}$ related activities.

The second paper, "Human-like Sensing for Robotic Remote Inspection and Analytics", by Arpan Pal, Ranjan Dasgupta, Arindam Saha, and Bhaskar Nandi introduces Human-like Sensing or "5 senses computing" as a natural futuristic extension of Internetof-Things. This paper discusses how 3D optical vision, thermal vision, acoustic profiling, olfaction, and tactile sensing can help in remote inspection and analytics solutions. Further, the authors propose a robot mounted opto-thermal and acoustic sensing system as a possible integrated system to gather such data.

The Third paper, "Future Wireless Systems for Human Bond Communications", by Enrico Del Re, Simone Morosi, Lorenzo Mucchi, Luca Simone Ronga, and Sara Jayousi aims to summarize the main feature of HBCs, describe a flexible architecture that could be adopted in these future systems, discuss how upcoming future wireless systems (e.g. upcoming 5G standards, Wireless Body Area Network, etc.) could eventually boost the HBC adoption, deal with the security and privacy issues, present the possible applications in multiple contexts and address the open points in the development of an HBC system.

The fourth paper, "Personalized Ubiquitous Health and Wellness Care: the KNOWLEDGECARE Vision", by Mauro De Sanctis proposes a new knowledge-based cross-disciplinary approach (including ICT engineering, business, systems medicine, telemedicine, and ethics) to attack the problem utilizing an e-health cloud platform, where the individuals can "upload" and "download" personal healthcare data and knowledge at the same time allowing healthcare stakeholders to do the same under the respective personal security and ethical rules.

The fifth paper, "Data Driven Wireless Network Design: a Multi-level Modelling Approach", by Carolina Fortuna, Eil De Poorter, Primoz Skraba, and Ingrid Moerman contributes two novel ideas namely, (i) the use of data driven multi-level analysis for understanding the behavior of wireless networks, and (ii) the identification of open challenges and directions for future research.

The sixth paper, "Multi Business Model Innovation in a World of 5G- What Will Persuasive Business Models Look Like in a World of 5G?", by Peter Lindgren describes a conceptual futuristic look to persuasive business models embedded with persuasive technologies with some preliminary case research. State-of-the art of on persuasive business model and persuasive technology research are presented and finally a summary is give on what we can expect in a future world of $5 \mathrm{G}$.

The seventh paper, "Dental and Biological Aspects for the Design of an Integrated Wireless Warning System for Implant Supported Prostheses", by Gianpaolo Sannino, Diego Sbardella, Ernestina Cianca, Marina Ruggieri, Massimo Coletta, and Ramjee Prasad proposes a system for an early warning on the prosthesis performance, in particular in terms of micro-displacements of the implant-prostheses connection, enabling actions to prevent fatal damages to the structure. The system includes a sensor for micro-displacement to be inserted in prosthesis volume, with embedded wireless communications capabilities. 
The eighth paper, "Network Neutrality Impact on Human Bond Communications", by Yapeng Wang and Ramjee Prasad reviews the development of Network Neutrality (NN) debate process, and the opinions from different sides, including network providers, service providers, other relevant companies, governments and researchers. This paper also discusses the emphasis of NN's impact on futuristic innovation, particularly on the Human Bond Communications.

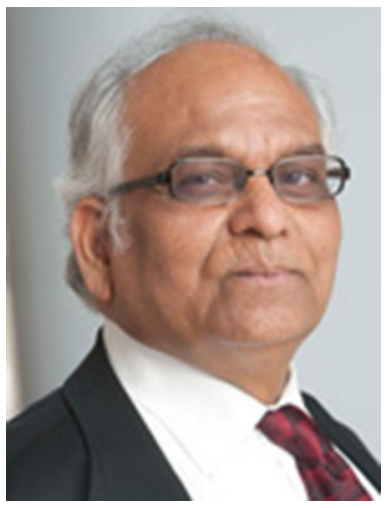

Ramjee Prasad has been holding the Professorial Chair of Wireless Information and Multimedia Communications at Aalborg University, Denmark (AAU) since June 1999. Since 2004, he is the Founding Director of the Center for TeleInfrastruktur (CTIF-http://www. ctifgroup.dk/), established as a large cross-/multi-disciplinary research center at the premises of Aalborg University. Under the leadership of Ramjee Prasad, CTIF has emerged as a prominent international center of excellence for his visionary ideas and path breaking research in wireless communications. CTIF boasts of a global presence today with its divisions dotted in eleven coutries (and counting) spanning across three continents. As well as, through the numerous valuable partnerships, it has forged with world renowned academic intitutions spread across fourteen countries and six continents. He is a Fellow of the Institute of Electrical and Electronic Engineers (IEEE), USA; the IET, UK; the IETE, India, the Wireless World Research Forum (WWRF), and a member of the Netherlands Electronics and Radio Society (NERG), and the Danish Engineering Society (IDA). For his exceptional contribution to the internationalization of the Danish telecommunication research and education, in 2010, Ramjee Prasad was awareded the Knight of the Order of Dannebrog (Ridderkorset af Dannebrogordenen2010) by the Queen of Denmark. Ramjee Prasad is the recipient of many international academic, industrial and governmental awards and distinctions. He has received many prestigious international awards such as: IEEE Communications Society Wireless Communications Technical Committee Recognition Award in 2003 for making contribution in the field of "Personal, Wireless and Mobile Systems and Networks", Telenor's Research Award in 2005 for impressive merits, both academic and organizational within the field of wireless and personal communication, 2014 IEEE AESS Outstanding Organizational Leadership Award for: "Organizational Leadership in developing and globalizing the CTIF (Center for TeleInFrastruktur) Research Network", and so on. He received honorable award with Gold Medal in 2014 from Academic Council of Technical University-Sofia, Bulgaria for his major contribution to the development of its international cooperation. He has published more than 30 books, 1000 plus journals and conferences publications, more than 15 patents, over $100 \mathrm{PhD}$ Graduates and larger number of Masters (over 250). Several of his students are today worldwide telecommunication leaders themselves. His research publications have been very well cited globally.

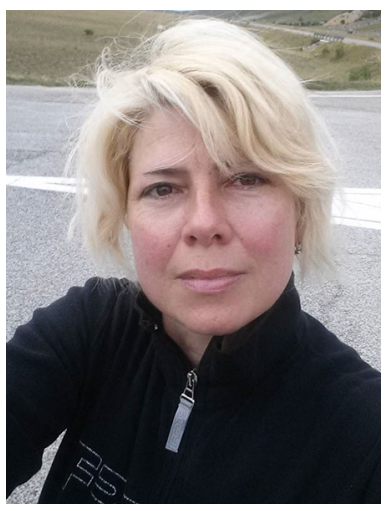

Marina Ruggieri is Full Professor of Telecommunications Engineering at the University of Roma "Tor Vergata" and therein member of the Board of Directors. She is IEEE 2016 Vice President-Elect, Technical Activities. She is Past Director of IEEE Division IX (2014-2015). She is member of the IEEE Governance, Public Visibility and Fellow Committees. She is Sr. past President of the IEEE Aerospace and Electronic Systems Society. She is proboviro of the Italian Industries Federation for Aerospace, Defense and Security (AIAD); member of the Technical-Scientific Committee of the Center for Aeronautical Military Studies. She has been Vice President of the Roma Chapter of AFCEA (2006-2015). She is co-founder and Chair of the Steering Board of the interdisciplinary Center for Teleinfrastructures (CTIF) at the University of Roma "Tor Vergata". The Center, that belongs to the CTIF global network, with nodes in USA, Europe and Asia, focuses on the use of the Information and Communications Technology (ICT) for vertical applications (health, energy, cultural heritage, economics, law) by integrating terrestrial, air and space communications, computing, positioning and sensing. She is Principal Investigator of the 40/50 GHz TPD\#5 Communications Experiment on board 
Alphasat (launched on July 2013). She received: 1990 Piero Fanti International Prize; 2009 Pisa Donna Award as women in engineering; 2013 Excellent Women in Roma Award; Excellent and Best Paper Awards at international conferences. She is IEEE Fellow. She is author/co-author of 330 papers, 1 patent and 12 books. 